\title{
HUBUNGAN PENDAMPINGAN SUAMI DENGAN TINGKAT KECEMASAN IBU PERSALINAN KALA 1 DALAM MENGHADAPI PROSES PERSALINAN
}

\author{
Selfi Indah Mayangsari ${ }^{1}$ \\ Politeknik Yakpermas Banyumas, Diploma III Keperawatan \\ Email : jurnalyakpermas@gmail.com \\ Sulistyowati ${ }^{2}$ \\ Politeknik Yakpermas Banyumas, Diploma III Keperawatan \\ Email : jurnalyakpermas@gmail.com \\ Eko Sari Ajiningtyas ${ }^{3}$ \\ Politeknik Yakpermas Banyumas, Diploma III Keperawatan \\ Email : jurnalyakpermas@gmail.com
}

\begin{abstract}
ABSTRAK
Di Indonesia terdapat 107.000 (28,7\%) ibu hamil yang mengalami kecemasan dalam menghadapi persalinan. Pada saat ini Angka Kematian Ibu (AKI) di Indonesia masih sangat tinggi. Menurut Survey Demografi dan Kesehatan Indonesia (SDKI) 2014 menyebutkan Angka Kematian Ibu 228 per 100.000 kelahiran hidup. Indonesia menduduki nomor 3 tertinggi di kawasan Asia Selatan dan Asia Tenggara untuk jumlah AKI. Indonesia sebagai salah satu Negara dengan AKI tertinggi Asia. Tujuan penelitian ini untuk Mengetahui hubungan suami terhadap tingkat kecemasan ibu persalinan kala 1 dalam menghadapi proses persalinan. Metode Penelitian ini menggunakan penelitian kepustakaan, waktu 22 November 2019 sampai 02 Juni 2020, sumber data 2 jurnal 1 buku, metode pengumpulan data dokumentasi, metode analisis deskriptif, organize, synthesize, identity. Hasil penelitian menunjukkan ada hubungan antara pendampingan suami dengan tingkat kecemasan ibu persalinan kala 1 dalam menghadapi proses persalinan dimana dampingan suaminya baik mengalami tingkat kecemasan ringan jika pendampingan suaminya kurang mengalami tingkat kecemasan berat
\end{abstract}

Kata kunci : Persalinan; Tingkat Kecemasan; Pendampingan Suami

\section{ABSTRACT}

In Indonesia, there are 107,000 (28.7\%) pregnant women who experience anxiety in facing childbirth. Currently, the Maternal Mortality Rate (MMR) in Indonesia is still very high. According to the 2014 Indonesian Demographic and Health Survey (IDHS), the Maternal Mortality Rate is 228 per 100,000 live births. Indonesia is the third highest in the South and Southeast Asia region for the number of MMR. Indonesia is one of the countries with the highest MMR in Asia. The purpose of this study was to determine the husband's relationship to the level of anxiety of the mother at stage 1 in dealing with the labor process. This research method uses library research, from 22 November 2019 to 02 June 2020, data sources 2 journals 1 book, documentation data collection method, descriptive analysis method, organize, synthesize, identity. The results showed that there was a relationship between husband's assistance and the level of anxiety of mothers who gave birth when they faced the labor process where their husband's assistance had mild anxiety if their husband's assistance had less severe anxiety.

Key words: childbirth; Anxiety Level; Husband's Assistance

\section{PENDAHULUAN}

Persalinan merupakan proses pergerakan keluarnya janin, plasenta, dan membrane dari dalam rahim melalui jalan lahir. Proses ini berawal dari pembukaan dan dilatasi serviks sebagai akibat kontraksi uterus dengan frekuensi, durasi, dan kekuatan yang teratur (Rohani, 2011).

Persalinan adalah proses pengeluaran hasil konsepsi (janin dan plasenta) yang telah cukup bulan atau dapat hidup di luar kandungan melalui jalan lahir atau melalui jalan lain, 
Selfi Indah Mayangsari : Hubungan Pendampingan Suami Dengan Tingkat Kecemasan Ibu Persalinan Kala 1 Dalam Menghadapi Proses Persalinan

dengan bantuan atau tanpa bantuan (Suliswaty \& Nugraheny, 2010).

Pada umumnya, seorang ibu yang mengalami kehamilan untuk pertama kalinya akan merasa senang dan semakin tinggi rasa ingin tau terhadap perubahan diri dan perkembangan janin. Tetapi disaat yang sama timbul pula rasa cemas dalam diri ibu hamil (Shodiqoh \& Syahrul, 2014).

Kecemasan adalah perasaan takut yang tidak jelas dan tidak didukung oleh situasi. Individu yang merasa cemas akan merasa tidak nyaman atau takut, namun tidak mengetahui alasan kondisi tersebut terjadi. Kecemasan tidak memiliki stimulus yang jelas yang dapat diidentifikasi (Videbeck \& Sheila, 2012).

Cemas (cemas) merupakan sebuah emosi dan pengalaman subjektif yang dialami sesorang dan berhubungan dengan perasaan yang tidak pasti dan tidak berdaya (Kusumawati \& Hartono, 2012).

Di Indonesia terdapat 107.000 $(28,7 \%)$ ibu hamil yang mengalami kecemasan dalam menghadapi persalinan (Mandagi, Pali \& Sinolungan, 2013). Pelayanan kesehatan Maternal dan Neonatal merupakan salah satu unsur penentu status kesehatan. Pada saat ini Angka Kematian Ibu (AKI) di Indonesia masih sangat tinggi. Menurut Survey Demografi dan Kesehatan Indonesia (SDKI) 2014 menyebutkan Angka Kematian Ibu 228 per 100.000 kelahiran hidup. Indonesia menduduki nomor 3 tertinggi di kawasan Asia Selatan dan Asia Tenggara untuk jumlah AKI. Ini menempatkan Indonesia sebagai salah satu Negara dengan AKI tertinggi Asia (Dinkes, 2015).

Salah satu penyebab lain tingginya angka kematian ibu di Indonesia adalah gangguan kondisi psikis pada ibu selama kehamilan, persalinan, lingkungan kurangnya peran keluarga, khususnya untuk memberikan motivasi dalam proses persalinan, karena tidak dapat dipungkiri bahwa dukungan dari berbagai pihak pada masa kehamilan dan persalinan sangat dibutuhkan untuk menenangkan kondisi fisik ibu (Mu'minah, 2013).

Dukungan suami dapat mengurangi kecemasan sehingga ibu hamil dapat merasa tenang dan memiliki mental yang kuat dalam menghadapi persalinan (Shodiqoh, 2014).

Secara psikologis, istri membutuhkan pendampingan suami selama proses persalinan dengan adanya kehadiran pendamping persalinan (suami) ibu dapat berbagi rasa sakit dan suami dapat memberikan penghiburan pada istri dan memberikan motivasi agar istri lebih kuat dalam menjalani proses persalinan. Dukungan yang terus menerus dari seorang pendamping persalinan kepada ibu selama proses persalinan dan melahirkan dapat mempermudah proses persalinan dan melahirkan, memberikan rasa nyaman, semangat, membesarkan hati ibu dan meningkatkan rasa percaya diri ibu, serta mengurangi kebutuhan tindakan medis (Taufik, 2010).

Penelitian lain tentang pendamping atau kehadiran orang kedua dalam proses persalinan, yaitu oleh Kristina (2010) menemukan bahwa para ibu yang didampingi seorang sahabat atau keluarga dekat (khususnya suami) selama proses persalinan berlangsung, memiliki resiko lebih kecil mengalami komplikasi yang memerlukan tindakan medis daripada mereka yang tanpa pendampingan. Ibu-Ibu dengan pendamping dalam menjalani 
persalinan, berlangsung lebih cepat dan lebih mudah. Dalam penelitian tersebut, ditemukan pula bahwa kehadiran suami atau kerabat dekat akan membawa ketenangan dan menjauhkan sang ibu dari stress dan kecemasan yang dapat mempersulit proses kelahiran dan persalinan.

Tujuan penelitian ini adalah untuk mengetahui hubungan pendampingan suami dengan tingkat kecemasan ibu persalinan kala 1 dalam menghadapi proses persalinan.

\section{METODE PENELITIAN}

Jenis penelitian ini adalah penelitian kepustakaan yaitu penelitian dengan mengkaji atau meninjau secara kritis pengetahuan gagasan, atau temuan yang terdapat dalam literature akademik dengan mencari referensi teori yang relevan dengan kasus atau permasalahan yang ditemukan. Referensi teori yang diperoleh dijadikan sebagai fondasi dasar dan alat utama bagi praktek penelitian (Syaodah,2013). Adapun sifat penelitian ini adalah analisis diskriptif, yaitu penguraian secara teratur data yang telah diperoleh dan kemudian diberikan pemahaman dan penjelasan agar dapat dipahami dengan baik oleh pembaca.

Sumber Data yang digunakan dalam penelitian ini adalah data sekunder. Data sekunder adalah data yang diperoleh bukan dari pengamatan langsung, tetapi diperoleh dari hasil penelitian yang dilakukan oleh peneliti-peneliti sebelumnya, yang berupa buku dan laporan ilmiah dalam artikel atau jurnal. Sumber utama pada penelitian ini menggunakan 2 jurnal penelitian, jurnal pertama berjudul "Hubungan Pendampingan Suami Dengan Tingkat Kecemasan Ibu Pada Fase Aktif Kala 1 Proses Persalinan Normal Di Ruang Bersalin RSUD
Kendal" yang diterbitkan pada tahun 2013 oleh Nelisa \& Anggorowati dan jurnal kedua berjudul "Hubungan Pendampingan Suami Dengan Tingkat Kecemasan Ibu Bersalin Kala I Di Ruang Bersalin Rumah Sakit Pertamina Bintang Amin" yang diterbitkan tahun 2015 oleh Rilyani.

Teknik pengumpulan data diantaranya menggunakan dokumentasi yang merupakan metode untuk mencari dokumen atau data-data yang dianggap penting melalui artikel koran/majalah, jurnal, pustaka, brosur, buku dokumentasi serta melalui media elektronik yaitu internet yang terkait rumusan masalah penelitian dan teknik pengumpulan data menggunakan studi literature yang merupakan cara yang dipakai untuk menghimpun data-data atau sumber-sumber yang berhubungan dengan topik yang diangkat dalam suatu sumber, jurnal, buku dokumentasi, internet, dan pustaka.

Data-data yang sudah diperbolehkan kemudian dianalisis dengan metode analisis deskriptif. Metode analisis deskriptif dilakukan dengan cara mendeskripsikan fakta-fakta yang kemudian dilanjutkan dengan analisis, tidak semata-mata menguraikan, melainkan juga memberikan pemahaman dan penjelasan secukupnya.

Prosedur penelitian ini melalui prosedur Organize yaitu mengorganisir literatur yang akan ditinjau dengan permasalahan dengan tahapan mencari ide, tujuan umum, dan simpulan dari literatur dengan cara membaca abstrak, beberapa pendahuluan, dan kesimpulannya; Synthesize yaitu menyatukan hasil organisir literatur menjadi suatu ringkasan agar menjadi satu kesatuan dan dengan cara mencari keterikatan antara literature dan Identify yaitu 
Selfi Indah Mayangsari : Hubungan Pendampingan Suami Dengan Tingkat Kecemasan Ibu Persalinan Kala 1 Dalam Menghadapi Proses Persalinan

mengidentifikasi isu-isu dalam literatur dianggap sangat penting untuk dibalas dan dianalisis untuk mendapatkan tulisan yang menarik ketika dibaca.

\section{HASIL DAN PEMBAHASAN}

Penelitian ini dilakukan pada ibu persalinan kala I di Ruang Bersalin RSUD Kendal dan di Ruang Bersalin Rumah sakit Pertamina Bintang Amin.

Tabel 1.Hubungan Pendampingan Suami Terhadap Tingkat Kecemasan Ibu Pada Fase Aktif Kala1 Proses Persalinan Normal di Ruang Bersalin RSUD Kendal Bulan Juli 2013 n=48

\begin{tabular}{|c|c|c|c|c|c|c|}
\hline \multirow{3}{*}{$\begin{array}{c}\text { Pend } \\
\text { am } \\
\text { pinga } \\
\text { n } \\
\text { Suam } \\
\text { i }\end{array}$} & \multicolumn{6}{|c|}{ Tingkat Kecemasan } \\
\hline & \multicolumn{2}{|c|}{$\begin{array}{c}\text { Cemas } \\
\text { Berat }\end{array}$} & \multicolumn{2}{|c|}{$\begin{array}{l}\text { Cemas } \\
\text { Sedang }\end{array}$} & \multicolumn{2}{|c|}{$\begin{array}{l}\text { Cemas } \\
\text { Ringan }\end{array}$} \\
\hline & $\mathbf{n}$ & $\%$ & $\mathbf{n}$ & $\%$ & $\mathbf{n}$ & $\%$ \\
\hline Baik & 2 & 15,4 & 10 & 58,8 & 15 & $\begin{array}{c}83, \\
3\end{array}$ \\
\hline $\begin{array}{c}\text { Cuku } \\
\mathrm{p} \\
\& \\
\text { Kura } \\
\text { ng }\end{array}$ & 11 & 84,6 & 7 & 41,2 & 3 & $\begin{array}{c}16, \\
7\end{array}$ \\
\hline & 13 & 100 & 17 & 100 & 18 & $\begin{array}{l}10 \\
0\end{array}$ \\
\hline
\end{tabular}

Berdasarkan tabel 1. didapatkan hasil bahwa dari 13 responden yang mengalami cemas berat, diketahui 2 responden $(15,4 \%)$ pendampingan suaminya baik, 11 responden $(84,6 \%)$ pendampingan suaminya cukup \& kurang. Dari 17 responden yang mengalami cemas sedang, diketahui 10 responden $(58,8 \%)$ pendampingan suaminya baik, 7 responden $(41,2 \%)$ pendampingan suaminya cukup \& kurang. Dari 18 responden yang mengalami cemas ringan, diketahui 15 responden $(83,3 \%)$ pendampingan suaminya baik, 3 responden $(16,7 \%)$ pendampingan suaminya cukup \& kurang.

Berdasarkan hasil penelitian dapat diketahui bahwa sebagian besar respondenyang mengalami kecemasan ringan, pendampingan suaminya baik. Hal ini terjadi karena pendampingan suami pada

persalinan istri dapat memberikan semangat

serta motivasi bagi istri dalam melakukan bersalin. Selain itu, dengan kehadiran suami

di samping istri pada saat persalinan akan memberikan rasa aman dan nyaman serta mengurangi perasaan cemas istri pada saat bersalin.

Hasil penelitian menunjukkan terdapat responden yang mengalami kecemasan berat, namun pendampingan suaminya baik. Hal ini terjadi karena responden baru pertama melahirkan, sehingga belum mempunyai pengalaman melahirkan, serta adanya responden yang berusia di bawah 20 tahun yang berarti masuk dalam kategori resiko tinggi bagi ibu untuk melahirkan, sehingga ibu merasa cemas. Hasil penelitian juga menunjukkan terdapat responden yang pendampingan suaminya kurang baik, namun mengalami cemas ringan. Hal ini terjadi karena ibu sudah pernah melahirkan sebelumnya, dan ibu mendapatkan informasi yang baik tentang persalinan saat melakukan pemeriksaan ANC.

Kehadiran suami atau pasangan sebagai pendamping persalinan sangat dianjurkan untuk mendampingi ibu selama persalinan, karena pendekatan langsung dapat mendorong komunikasi diantara pasangan sehingga dapat mengatasi semua kekhawatiran dan kecemasan yang munculpada ibu selama proses 
persalinan, sehingga dapat mengatasi stress pesikologis dan hipoksia yang dapat meningkatkan sekresi adrenalin tersebut. Dengan kehadiran suami di samping ibu selama proses persalinan ibu akan merasa lebih tenang dan nyaman, ibu merasakan suami ikut menanggung beban dirinya, ibu dapat mengalihkan perasaan cemas yang muncul dengan berkomunikasi dengan suami, ibu merasakan mendapatkan semangat dan rasa percaya diri dari kehadiran suami di sampingnya selama proses persalinan.

Tabel 2. Hubungan Pendampingan Suami Terhadap Tingkat Kecemasan Ibu Bersalin Kala 1 DI RS Pertamina Bintang Amin Tahun 2015

\begin{tabular}{ccccccc}
\hline $\begin{array}{c}\text { Tingkat } \\
\text { Kecemasa } \\
\mathbf{n}\end{array}$ & $\begin{array}{l}\text { Pendam } \\
\text { pingan } \\
\text { Kasus }\end{array}$ & $\begin{array}{c}\text { Suami } \\
\text { Kontrol }\end{array}$ & Total \\
& & & & & & \\
\cline { 2 - 7 } $\mathbf{n}$ & $\%$ & $\mathbf{n}$ & $\%$ & $\mathbf{n}$ & $\%$ \\
\hline Cemas & 3 & 10, & 1 & 63, & 3 & 10 \\
sedang - & & 0 & 9 & 3 & 0 & 0 \\
cemas & & & & & & \\
berat & & & & & & \\
\hline Tidak & 2 & 90, & 1 & 36, & 3 & 10 \\
cemas - & 7 & 0 & 1 & 7 & 0 & 0 \\
cemas & & & & & & \\
ringan & & & & & & \\
\hline Jumlah & 3 & 63, & 3 & 36, & 6 & 10 \\
& 0 & 3 & 0 & 7 & 0 & 0 \\
\hline
\end{tabular}

Berdasarkan tabel 2. didapatkan hasil bahwa analisis hubungan antara pendampingan suami dengan tingkat kecemasan diperoleh sebanyak 3 (10.0\%) ibu dengan didampingi suami mempunyai tingkat kecemasan sedang - cemas berat. Sedangkan diantara ibu dengan tidak didampingi suami, ada 19 (63.3\%) ibu yang mengalami cemas ringan cemas berat.

Menurut analisa peneliti, ibu bersalin yang didampingi suami merasa lebih tenang dan nyaman karena mereka memiliki teman untuk berbagi rasa sakit dan cemas akan semua proses persalinan dan saat-saat menunggu kelahiran bayi mereka. Sebaliknya walaupun tidak didampingi suami ada ibu yang mengalami tidak cemas sampai dengan cemas ringan ini dipengaruhi oleh beberapa faktor antara lain : ibu yang memang lebih tenang didampingi orang tua atau keluarganya, ibu yang mengerti suaminya mempunyai tugas atau pekerjaan yang tidak bisa ditinggalkan.

Kehadiran suami saat persalinan saat persalinan akan membawa ketenangan dan menjauhkan sang ibu dari stress. Kehadiran suami akan membawa hal positif secara psikologis, dan berdampak positif pada kesiapan ibu secara fisik. Kehadiran suami sentuhan tangannya, doa dan kata-kata penuh motivasi yang diucapkannya akan membuat istri merasa lebih kuat dan tabah menghadapi rasa sakit dan kecemasannya serta memiliki motivasi untuk berjuang melahirkan bayinya.

Namun demikian, ada 3 ibu $(10.0 \%)$ yang didampingi suami tingkat kecemasannya ada di cemas sedang - berat.Hal ini dikarenakan baru mengalami kehamilan yang pertama.Dimana ibu yang hamil untuk pertama kali belum mengalami persalinan, sehingga menyebabkan ibu tidak tenang dalam menghadapi persalinan. Sedangkan ibu yang sudah pernah menghadapi hamil dan melahirkan, akan merasa lebih tenang dalam menghadapi persalinan. Dengan adanya pengalaman hamil ataupun melahirkan, ibu akan lebih dapat menyesuaikan diri dengan kehamilan ataupun persalinannya.

Sejalan dengan teori yang dikemukakan Nolan (2010), 
Selfi Indah Mayangsari : Hubungan Pendampingan Suami Dengan Tingkat Kecemasan Ibu Persalinan Kala 1 Dalam Menghadapi Proses Persalinan

kehamilan pertama bagi seorang wanita merupakan salah satu periode kritis dalam kehidupannya. Pengalaman baru ini memberikan perasaan yang bercampur baur antara bahagia, dengan kekhawatiran akan apa yang akan dialaminya selama masa kehamilan dan persalinan.

Hasil penelitian diatas juga terdapat $11 \mathrm{ibu}(36,7 \%)$ yang tidak didampingi suami mengalami tidak cemas - ringan hal ini dikarenakan ibu lebih nyaman dan tenang jika didampingi ibunya atau keluarganya. Serta dipengaruhi oleh faktor usia, sebagian ibu hamil berada pada usia produktif yaitu 20-35 tahun. Sehingga ibu dari segi usia dapat dikategorikan sudah siap secara fisik dan mental dalam menghadapi kehamilan dan persalinan

\section{PEMBAHASAN}

\section{Tabel 3. Persamaan Kedua Jurnal}

\begin{tabular}{llcr}
\hline No & \multicolumn{3}{c}{ Persamaan } \\
\hline 1. & Tujuan dari & penelitian ini untuk \\
& mengetahui & adanya hubungan \\
& pendampingan & suami dengan tingkat \\
& kecemasan ibu persalinan kala I.
\end{tabular}

2. Menggunakan teknik accidental sampling dan penggumpulan data menggunakan kuesioner kecemasan.

3. Hasil penelitian menunjukan bahwa ada hubungan pendampingan suami terhadap tingkat kecemasan ibu prsalinan kala 1, sebagian besar pendampingan suaminya baik dengan tingkat kecemasan ringan

\section{Tabel 4. Perbedaan Kedua Jurnal}

\begin{tabular}{cl}
\hline No & \multicolumn{1}{c}{ Perbedaan } \\
\hline 1. & Jurnal 1 diterbitkan tahun 2013 oleh \\
& $\begin{array}{l}\text { Nelisa \& Anggorowati dan Jurnal 2 } \\
\text { diterbitkan tahun 2015 oleh Rilyani. }\end{array}$ \\
& Lokasi penelitian jurnal 1 di Ruang \\
2. & $\begin{array}{l}\text { Bersalin RSUD Kendal dan jurnal 2 di } \\
\text { RS Pertamina Bintang Amin Bandar } \\
\text { Lampung. }\end{array}$ \\
\hline
\end{tabular}

Responden penelitian jurnal 1 adalah ibu persalinan kala 1 fase aktif dengan

3. jumlah 48 responden dan responden penelitian jurnal 2 adalah ibu persalinan kala 1 fase laten dengan jumlah 60 responden.

Metode penelitian jurnal 1 menggunakan studi korelatif dengan pendekatan cross sectional dan jurnal

4. 2 menggunakan penelitian kuantitatif dengan rancangan analtik observasional dengan pendekatan case control.

Hasil telaah 2 jurnal didapatkan perbedaan dan persamaan antara kedua jurnal dan data rata-rata tingkat kecemasan pada bulin kala 1 yang didampingi suami berada dalam tingkat kecemasan ringan sebanyak $64,15 \%$ dengan pendampingan yang baik $83,3 \%$ dan pendampingan yang cukup $16,7 \%$.

Hal ini sejalan dengan teori yang di kemukakan oleh Sari \& Rimandini (2014), peran serta orangorang terdekat dicintai sangat besar pengaruhnya terhadap psikologi ibu bersalin biasanya sangat akan membutuhkan dorongan dan kasih sayang yang lebih dari seorang yang dicintai untuk membantu kelancaran jiwa ibu itu sendiri.

Didukung dengan teori Nisman (2011), kondisi psikologis cemas sangat berpengaruh pada fungsi tubuh secara fisik. Pada saat seorang cemas pembuluh darah mengalami vasokontriksi atau menyempit sehingga aliran darah keseluruh tubuh akan terhambat atau berkurang. Hal ini akan sangat berpengaruh pada fungsi organ-organ misalnya organ-organ yang terlibat dalam persalinan menjadi tidak dapat berfungsi dengan baik. Tenaga mengejan menjadi kurang kuat, dorongan dari dalam tubuh juga tidak kuat sehingga menghambat proses persalinan dengan kehadiran 
suami sentuhan tangannya, doa dan kata-kata penuh motivasi yang diucapkannya akan membuat istri merasa lebih kuat dan tabah menghadapi rasa sakit dan kecemasanya serta memiliki motivasi untuk berjuang melahirkan bayinya. Hal ini sejalan dengan penelitian Rosdiana (2018) menunjukkan bahwa pendampingan suami saat persalinan mempunyai peranan penting bagi ibu karena dapat mempengaruhi psikologis ibu. Kondisi psikologis yang nyaman, rileks dan tenang dapat terbentuk melalui dukungan kasih sayang keluarga. Bentuk dukungan bisa berupa support mental, berbagi pengalaman saat menjalani proses persalinan, atau halhal positif lain, sehingga berpengaruh pada kekuatan ibu saat melahirkan bayinya dan juga dapat memberi dorongan dan keyakinan pada ibu selama proses persalinan berlangsung dan membantu ibu untuk menciptakan suasana nyaman dalam ruang bersalin.

Gejala yang timbul saat cemas dapat berupa gelisah, pusing, jantung berdebar, dan gemeteran. Tingkat kecemasan digolongkan menjadi 4 tingkat kecemasan yaitu kecemasan ringan, kecemasan sedang, kecemasan berat dan kecemasan sangat berat. Ibu persalinan dalam menghadapi proses persalinan yang mengalami kecemasan ringan ditandai dengan gejala sedikit gelisah atau rileks, percaya diri, waspada, sedikit tidak sabar, memperhatikan banyak hal, ketegangan otot ringan, dan sadar akan lingkungan, jika ibu mengalami kecemasan berat ditandai dengan gejala sulit berfikir, sangat cemas, berkeringat banyak, takut, bingung, menarik diri, penyelesaian masalah buruk, kontak mata buruk, bicara cepat, rahang menegang, dan gemeter.
Menurut sutejo (2018), tanda dan gejala pasien dengan kecemasan adalah cemas, khawatr, firasat buruk, takut akan pikirannya sendiri serta mudah tersinggung, tegang, tidak tenang, gelisah dan mudah terkejut.

$$
\text { Adanya }
$$

hubungan

pendampingan suami dengan tingkat kecemasan ibu persalinan kala 1 dalam menghadapi proses persalinan. Apabila pendampingan suami baik maka tingkat kecemasan ibu menjadi kecemasan ringan, jika pendampingan suami kurang maka tingkat kecemasan ibu menjadi kecemasan berat. Hal ini terjadi karena pendampingan suami pada persalinan dapat memberikan pendampingan fisik maupun psikis secara terus menerus dan berkesinambungan dalam mengikuti seluruh prosedur persalinan mulai kala 1 sampai kala IV terutama memberikan semangat serta motivasi bagi istri saat persalinan, selain itu dengan kehadiran suami di samping istri pada saat persalinan akan memberikan rasa aman dan nyaman serta mengurangi perasaan cemas istri pada saat proses persalinan.

\section{SIMPULAN}

Dari hasil penelitian yang dilakukan adanya hubungan antara pendampingan suami dengan tingkat kecemasan ibu persalinan kala 1 dalam menghadapi proses persalinan sehingga kecemasan ibu dalam menghadapi proses persalinan dengan pendampingan suami baik maka tingkat kecemasan ibu menjadi kecemasan ringan, jika pendampingan suami kurang tingkat kecemasan ibu menjadi kecemasan berat.

\section{SARAN}

Disarankan tenaga kesehatan menghadirkan suami dalam proses persalinan, diharapkan di dalam ruang 
Selfi Indah Mayangsari : Hubungan Pendampingan Suami Dengan Tingkat Kecemasan Ibu Persalinan Kala 1 Dalam Menghadapi Proses Persalinan

bersalin sebagai pendamping persalinan dan lebih memperhatikan kecemasan ibu bersalin kala I, dengan memberikan bantuan dan dukungan fisik maupun emosional pada ibu agar tingkat kecemasan berkurang sehingga seluruh rangkaian proses persalinan berlangsung dengan aman baik bagi ibu maupun bagi bayi yang dilahirkan.

\section{DAFTAR PUSTAKA}

Andriana, E. (2007). Melahirkan Tanpa Rasa Sakit (dengan Metode Relaksasi HypnoBirthing). Edisi Revisi. Jakarta: Penerbit PT. Bhuana Ilmu Populer.

Sulistyawati, A., Nugraheny, E . (2010). Asuhan Kebidanan pada Ibu Bersalin. Jakarta: Salemba Medika.

Chapman, V. (2006). Asuhan Kebidanan Persalinan Dan Kelahiran. Jakarta: EGC.

Dinkes. (2011). Profil Dinas Kesehatan Provinsi Jawa Tengah. Semarang: Dinkes Provnisi Jawa Tengah.

Hamilton, (2005). Dasar-dasar Keperawatan Maternitas. Jakarta: EGC..

Kusumawati, F., Hartono, Y. (2012). Buku Ajar Keperawatan Jiwa. Jakarta: Salemba Medika.

Lutfa, U., Maliya, A. (2008). Faktorfaktor yang mempengaruhi kecemasan pasien dalam tindakan kemoterapi di rumah sakit Dr. Moewardi Surakarta. (Skripsi thesis Universitas Muhammadiyah Surakarta, 2008). Diperoleh dari eprints.ums.ac.id.

Maimunah, S., (2009). Kecemasan Ibu hamil Menjelang Persalinan Pertama. HUMANITY. Vol V: 61-62.
Majid, dkk. (2011). Keperawatan Perioperatif. Gosyen. Publishing: Yogyakarta.

Mandagi, D. V., Pali, C., \& Sinolungan, J. S. (2013). Perbedaan Tingkat Kecemasan pada Primigravida dan Multigravida $d$ i RSIA Kasih Ibu Manado. Jurnal eBiomedik, 1(1)

Mu'minah, I., \& Mawarti, R. (2013). Hubungan Dukungan Sosial Dengan Tingkat Kecemasan Ibu Bersalin Kala I di Puskesmas Mergangsan Kota Yogyakarta (Doctoral dissertation, STIKES'Aisyiyah Yogyakarta).

Nelisa, T. S., \& Anggotowati, A. (2013). Hubungan pendampingan suami terhadap tingkat kecemasan $i$ bu pada fase aktif kala $I$ proses persalinan normal di ruang bersalin RSUD Kendal. Jurnal Keperawatan Maternitas Persatuan Perawat Nasional Indonesia.

Nisman, A, W. (2011). Ternyata Melahirkan Itu Mudah Dan Menyenangkan, CV Andi Offset, Yogyakarta.

Nolan, M. (2010). Kelas Bersalin, Golden Books: Yogyakarta.

Primasnia. P, Wagiyo, Elisa. (2013). Hubungan Pendampingan Suami Dengan Tingkat Kecemasan Ibu Primigravida Dalam Menghadapi Proses Persalinan Kala $I$ Di Rumah Bersalin Kota Ungaran. Dikutip dari:hhtps://scholar.goegel.co.i d

Rilyani, R. (2017). Hubungan Pendampingan Suami Dengan Tingkat Kecemasan $\quad \mathrm{lbu}$ Bersalin (Kala I) Di Ruang 
Bersalin Rumah Sakit

Pertamina Bintang Amin

Bandar Lampung Tahun

2015. Holistik

Jurnal

Kesehatan, 11(3), 188-195.

Rohani. (2011). Asuhan Kebidanan

Pada Masa Persalinan.

Jakarta: Salemba Medika.

Rohma, N. (2010). Pendidikan

Prenatal Upaya Promosi

Kesehatan Bagi Ibu Hamil. Jakarta: Gramata Publishing.

Sari, P, E \& Rimandini, D, K. (2014). Asuhan Kebidanan Persalinan (Intranatal Care), CV Trans Info Media, Jakarta.

Schlaepfer, T, E. (2012). Neurbiologu Of Psychiatric Disordes. Amsterdan: British Library Catologiung.

Shodiqoh, E.R., \& Syahrul, F. (2014). erbedaan Tingkat Kecemasan dalam Menghadapi Persalinan antara Primigravida dan Multigravida. Jurnal Berkala Epidemiologi. 2(1), 141-150. Diterima dari http://www.jounal.unair.ac.id/d ownload-full/JBE8534.

[Diakses pada tanggal 18 September 2017].

Smeltzer, C.Suzane. (2002). Buku Ajar Keperawatan Medikal Bedah (Ed.8), Vol 3, EGC, Jakarta.

Soerjono, S . (2002). Sosiologi. Jakarta: Raja Persada.

Stuart, G.W. (2007). Buku Saku Keperawatan Jiwa Edisi 5. Jakarta: EGC.

Sumarah, (2009). Perawatan IbuBersalin : Asuhan Kebidanan Pada Ibu Bersalin. Yogyakarta : Fitramaya.

Taufik. (2010). Psikologi Untuk Kebidanan. Surakarta: Eastview.
Tursilowati, S, Y., Sulistyorini, E. (2007). Pengaruh Peran Serta Suami Terhadap Tingkat Kecemasan Ibu Hamil Dalam Menghadapi Proses Persalinan. Dikutip dari:hhtps://scholar.goegel.co.i d

Videbeck, Sheila (2012). Buku Ajar Keperawatan Jiwa (Renata Komalasari, penerjemah). Jakarta: EGC.

Widya, N, I, S. (2018). Hubungan Dukungan Suami Dengan Tingkat Kecemasan Menghadapi Persalinan Pada Ibu Hamil Primigravida Trismeter III DI Puskesmas Melati II Sleman. Dikutip dari:hhtps://scholar.goegel.co.i d 